\title{
Moral y Traveling Compromiso ético y discurso de la forma en Cahiers du cinéma
} David Oubiña*

\author{
Universidad de Buenos Aires
}

Recibido 11 de abril 2020; aprobado 9 de julio de 2020

\begin{abstract}
Resumen
"La moral es una cuestión de travellings": la sentencia de Luc Moullet se hizo rápidamente célebre y -repetida de manera simplificada, imprecisa o directamente errónea- se convirtió en uno de los slogans teóricos de Cahiers du cinéma. La cita pone en escena el complejo vínculo que se establece entre la forma del film y la ética de su director. En ese sentido, el crítico se interroga sobre el modo en que las películas deben representar el mundo, pero también qué muestran las imágenes y cómo deberían ser vistas. Ese vínculo entre los travellings y la moral fue retomado y reformulado por Jean-Luc Godard y por Jacques Rivette: en el trayecto, el sentido original de la frase varía de manera casi imperceptible pero, a la vez, es sometido a transformaciones profundas. Durante la década de 1960, las reflexiones sobre el estilo de los cineastas pasarán rápidamente desde una valoración despolitizada a la radicalización ideológica. ¿Dónde radica el compromiso ético de un cineasta? ¿En su intención o en su estilo? Este artículo revisa las tensiones que atraviesan el pensamiento de la revista a propósito de la moral de los procedimientos.
\end{abstract}

Palabras Clave: Luc Moullet | Jean-Luc Godard | Jacques Rivette | Serge Daney | Forma y moral

Moral and Traveling. Ethical commitment and formal statements in Cahiers du cinéma

\begin{abstract}
"Morality is a question of tracking shots": Luc Moullet's statement quickly became famous and -repeated in a simplified, imprecise or wrong manner- was hailed as one of the theoretical slogans of Cabiers du cinéma. The statement stages the complex link between film's form and the director's ethics. In this sense, the critic wonders about how films should represent the world, but also what the images show and how they should be watched. The link between tracking shots and morality was revisited and reformulated by Jean-Luc Godard and Jacques Rivette: in this process, the original meaning of the statement varies almost imperceptibly but, at the same time, is subjected to profound transformations. During the 1960s, reflections on the filmmakers' style quickly shifted from depoliticized assessment to ideological radicalization. Where does a filmmaker's ethical commitment lie? In his intention or in his style? This article reviews the tensions that run through the journal in reference to the morality of forms.
\end{abstract}

Keywords: Luc Moullet | Jean-Luc Godard | Jacques Rivette | Serge Daney | Form and morality

\section{Introducción}

Fin de la década de 1950: luego de casi diez años de polémicas, Cahiers du cinéma ha triunfado y ha impuesto sus ideas. Aunque eso también puede volverse un inconveniente para una publicación que siempre había vivido del conflicto. La provocación de los "jóvenes turcos", a menudo caprichosa y violenta, había estado contaminada por cierto juvenilismo reaccionario; no obstante, su irreverencia había puesto en cuestión el conjunto de convenciones anquilosadas en que se apoyaba la crítica, había importado nuevos parámetros para vincularse con los films y había expandido las fronteras de lo cinematográfico. Lo cierto es que más allá de las disputas (luego de las disputas), la revista había conseguido imponer su agenda en el debate crítico. Aunque fuera por las malas razones, había logrado mostrar que tenía razón.

Según la política de los autores, lo que importa es el estilo: "No hay obras, sólo autores", escribe Truffaut citando a Giraudoux (1954, p. 4). Los grandes cineastas poseen un estilo inconfundible; por eso no hay diferencia entre sus buenas y malas películas, porque en todas es posible reconocer esa singular visión sobre el mundo expresada según la puesta en escena. Cuando Georges Sadoul se queja frente al desinterés de los jóvenes críticos por el contenido y el tema, André Bazin sale en defensa de sus discípulos. Luego de admitir que ni Truffaut ni Rohmer ni Rivette son precisamente escritores

* doubinia@retina.ar 
de izquierda, declara que de todos modos ninguno de sus colaboradores practica una estética fascista o ultra reaccionaria:

\begin{abstract}
Puedo asegurarle que el problema no es de ninguna manera político; incluso si una tendencia juvenil por la provocación y la polémica se presta a veces a la confusión, la cuestión es solamente crítica. 'Nuestros hitchcock-hawksianos' - para recuperar el epíteto que usted ha felizmente creado- representan ante todo a una generación de fanáticos del cine cuya parcialidad sólo se ve igualada por la erudición y de la cual pensamos, Jacques y yo, que merece ser escuchada, incluso si no sabe reclamar esto de otra manera que con cierta insolencia. Si tuviera que calificarla, la llamaría con gusto 'neoformalismo' porque sus criterios son muy diferentes de los del formalismo tradicional, que eran en su mayoría plásticos. Integran, en gran medida, el estilo del guión y postulan la continuidad del genio en los autores (citado en de Baecque, 2003, pp. 183-184).
\end{abstract}

Si Bazin defiende -aunque no comparte- el neoformalismo de sus discípulos es porque advierte allí un intento por entender los films a partir del estilo, antes que una descripción superficial de sus aspectos meramente retóricos. Las preocupaciones de Cahiers du cinéma siempre estarán del lado de la forma. Pero Bazin muere en 1958 y, durante la década de 1960, las reflexiones sobre el estilo de los directores atravesarán por una serie de mutaciones: rápidamente se pasará de una valoración despolitizada a la radicalización ideológica. ¿Dónde radica el compromiso ético de un cineasta? ¿En su intención o en su estilo? Este artículo revisa las tensiones que surcan el pensamiento de la revista a propósito de la moral de los procedimientos.

\section{Luc Moullet: la moral de la forma}

Los jóvenes directores norteamericanos -escribe Luc Moullet en 1959- no tienen nada para decir, y Sam Fuller aún menos que los demás. Hay algo que quiere hacer y lo hace naturalmente, sin esfuerzo. Esto no es un elogio mezquino: detestamos a esos filósofos frustrados que se ponen a hacer cine a pesar del cine y sólo repiten los descubrimientos de las otras artes, ésos que quieren expresar temas dignos de interés con un cierto estilo artístico. Si tienen algo para decir, díganlo, escríbanlo, predíquenlo si les da la gana, pero déjennos en paz (1959, p. 11).

Moullet (1959) empuja más al extremo (si eso fuera posible) el formalismo de la política de los autores: el cine no es un vehículo para que abusen de él intelectuales o filósofos sino un medio autónomo que se rige por sus propias reglas. Y sólo algunos pocos saben controlarlas con maestría. Tal como había sucedido unos años antes con los primeros hitchock-hawksianos, Moullet defiende a Fuller frente a las imputaciones por fascista y por anticomunista. Si rechaza esas denuncias se debe a que el cineasta -tan viril y tan decidido en apariencia- es el maestro de la ambigüedad. Dice: "A propósito del fascismo, sólo el punto de vista de alguien que ha sufrido la tentación tiene algún interés”. En Sed de mal (1958), Welles contrapone la dimensión estética del mal (Quinlan) y la dimensión moral del bien (Vargas): una y otra funcionan como absolutos complementarios. En El Diablo de las aguas turbias (1954) o en Casco de acero (1951), en cambio, Fuller permanece en el terreno de lo relativo donde no hay síntesis posible. Ética y violencia conviven, porque cada una sirve para contener los desbordes de la otra. La distinción es inteligente y sutil: aunque Moullet admite que Welles puede ser un artista mayor, Fuller actúa de manera menos mecánica y no cede ante la mala conciencia. Es “fáustico por principio y prometeico de hecho" (p. 19).

El crítico utiliza esos mismos argumentos a propósito de El rata (Sam Fuller, 1953) que había sido muy cuestionado nueve años antes en el Festival de Venecia y que había generado el conflicto entre el stalinista Georges Sadoul y los críticos de Cahiers du cinéma. Moullet admite que la película es propaganda de derecha, pero señala que su anticomunismo se limita al tema: "Ni los encuadres, ni la mezcla de sonido, ni el dosificado son moscófobos (...) La propaganda no va muy lejos porque los comunistas de Fuller no tienen nada de marxistas en su comportamiento" (1961, p. 48). Si la censura francesa ha retocado el film y ha podido reconvertir el espionaje en tráfico de drogas, eso es porque su trama política resulta un aspecto superficial que no define su sentido. ${ }^{1}$ Por lo tanto, es posible abstraerse del contenido ideológico y apreciar la nueva poesía creada por el cineasta. Es cierto que el fascismo y el anticomunismo son el tema de sus películas, pero sólo el tema. Porque los enemigos son convencionales y abstractos. El director confunde comunismo y gangsterismo o comunismo y nazismo por motivos comerciales: "Fascismo de gestos más que de intenciones. Porque no parece que Fuller sea tan fuerte en política” (Moullet 1959, p. 13). A Moullet no le interesa la ideología del cineasta porque lo que analiza es la moral que puede advertirse en la puesta en escena de sus films. Hay allí un "sentimiento poético por el movimiento de la cámara. Para muchos directores ambiciosos, los movimientos de la cámara dependen de la composición dramática. Nunca para Fuller en cuya obra son, por fortuna, totalmente gra- 
tuitos: es en función del poder emotivo del movimiento que se organiza la escena" (1959, p. 14). ${ }^{2}$

La forma de la expresión no está atada al contenido y, a menudo, lo contradice. En esa libertad de movimientos, el estilo encuentra su soberanía. En un artículo sobre Douglas Sirk, Moullet también celebra los efectos visuales de Los diablos del aire (Douglas Sirk, 1957) justamente porque no tienen ninguna funcionalidad argumental. "En el arte no hay más que artificio: elogiemos el artificio cultivado sin remordimientos, que así adquiere una sinceridad segunda, en vez del artificio enmascarado para sí mismo como para los demás bajo pretextos hipócritas. Lo verdadero es tan falso como lo falso, sólo lo muy falso deviene verdadero" (Moullet, 1958, p. 56). Aun así, hay diferencias. Porque en el caso de Sirk, el exceso es un resultado de un procedimiento; en cambio, Fuller está fascinado por el espectáculo del mundo material. Es un cineasta de lo telúrico, del instinto, de lo primitivo. Significativamente, la afirmación de Moullet se rige por un principio idealista. La discusión sobre la moral queda acotada a la dimensión de las formas o, en todo caso, señala que la estética tiene sus propias reglas. No hay, para el arte, otra moral que la moral de sus formas. Finalmente, un cineasta sólo está obligado a llevar sus travellings a buen término. El dictum de Luc Moullet se hizo rápidamente célebre y -repetido de manera simplificada, imprecisa o directamente errónea- se convirtió en uno de los slogans de Cahiers du cinéma: "La moral es una cuestión de travellings" [La morale est affaire de travellings] (1959, p. 14). ${ }^{3}$

\section{Jean-Luc Godard: la forma moral}

Poco después, en julio de ese mismo año, Godard recupera la sentencia aunque invierte los términos: "Los travellings son una cuestión moral" [Les travellings sont affaire de morale]. Parece más o menos lo mismo, pero no lo es. Moullet separa al film del mundo: las cosas pierden su estatuto natural sobre la pantalla porque pasan a regirse por otras reglas que son las del cine. Godard, en cambio, fusiona al film con el mundo: convoca al mundo a comparecer en la pantalla y hace que la película nos devuelva una imagen más precisa de lo real. El cine tiene sus propias reglas pero sólo adquieren sentido si logran mostrar lo real. En última instancia, cada película será juzgada por el modo que ha elegido para dar a ver.

Tal como lo plantea Moullet, no hay, para el arte, otro compromiso que la moral de sus formas. Según la variación de Godard, sin embargo, se trata de leer la moral en las formas: no dice que habría dos dimensiones de la moral (una para el mundo y otra para la obra) sino que hay una sola, pero su sentido debe ser leído en la superficie del film. La afirmación de Godard pretende responder a una pregunta de Doniol-Valcroze que, en realidad, ha sido formulada para Eric Rohmer durante una mesa redonda sobre Hiroshima mon amour (Alain Resnais, 1959). Rohmer es el único de los que participan en ese debate que esboza ciertas dudas sobre el film de Resnais. Dice: "Se puede amar y admirar Hiroshima mon amour y a la vez considerar que, por momentos, resulta bastante irritante" (Jean Domarchi et al, 1959, p. 5). Doniol pide la aclaración: ¿se trata de algo que resulta irritante en términos morales o en términos estéticos? Entonces interviene Godard (se podría intuir en la desgrabación, el apuro por responder, casi pisando el final de la pregunta): "Es lo mismo -afirma. Los travellings son una cuestión moral” (p. 5).

¿Qué es lo que Godard ha dicho? Que moral y estética son la misma cosa. Hablar de un travelling supone, de manera ineludible, evaluar la moral que se expresa en él. En todo caso, el estilo de un film es el modo en que el cine discurre sobre la moral. Quizás sin advertirlo y sin intención, Godard introduce una cuña en el silogismo de Moullet. Decidir qué mostrar y qué dejar afuera del encuadre es una resolución fundamental que no atañe a la pericia técnica de manera excluyente; en esa decisión sobre hacer o no hacer un movimiento de cámara, cómo hacerlo, cuánto debería durar, hasta dónde llevarlo y desde qué distancia, se juega toda la moral de un cineasta. Moullet separa al film del mundo: una vez representadas sobre la pantalla, las cosas pierden su estatuto referencial y pasan a regirse por otras reglas que son las del cine. Godard, en cambio, arrastra las cosas hacia el cine: la película tiene sus propias maneras de lidiar con el mundo, es cierto, pero aunque no se confunden, tampoco existen separados.

Para Godard, un gran director no es el que sabe usar sus dispositivos técnicos de manera adecuada "según las reglas del buen arte" (así como, en farmacología, se dice acerca de una receta magistral: "prepárese según arte") y tampoco es el que se siente obligado a ponerlos al servicio de una buena causa; un gran director es aquel que advierte el mandato moral implicado en su técnica. Es decir: el que entiende que sus instrumentos sólo se usan con justeza cuando son usados según una convicción sobre lo que es justo. La inversión que introduce Godard resulta fundamental no sólo porque altera (de manera leve pero decisiva) el carácter de la sentencia sino por- 
que revela, en el seno de la revista, un momento de cierta confusión donde se superponen actitudes que luego se volverán contradictorias. ${ }^{4}$

"La moral es una cuestión de travellings" / "El travelling es una cuestión moral”: Godard no tiene ninguna intención de polemizar con Moullet. Al contrario. Por otra parte, la frase pasa casi inadvertida, como arrojada en el vacío, porque no es expandida o cuestionada por los demás participantes de la mesa redonda. Más bien es borrada por la intervención de Pierre Kast que, como si no la hubiera escuchado, dirige la conversación hacia los vínculos entre cine y literatura en Resnais. No obstante, el contexto del debate resulta significativo. Antes de realizar Hiroshima mon amour, Resnais ya era el director de Noche y niebla (1956): un cineasta obsesionado por la memoria de la guerra y por el compromiso de recordar, un artista profundo destinado a grandes obras. En 1959, Resnais era el director más respetado por los cineastas de Nouvelle vague que, en esos momentos, comenzaban a rodar sus primeros films. En otros ámbitos, sin embargo, Hiroshima mon amour había sido acusada de ser una película muy literaria que se apoyaba excesivamente en el guión y en los diálogos de Marguerite Duras. Es decir un cineasta "poco cinematográfico". Es a propósito de ese director que Godard señala la importancia moral de los travellings: como si quisiera rescatar que toda la pericia técnica y todo el compromiso moral del film radican en el genio de Resnais.

\section{Jacques Rivette: la forma abyecta}

La expresión teórica más acabada de los planteos de Godard (la más virulenta y la más extrema) está enunciada en "De la abyección", el artículo que Rivette escribe sobre Kapo (1960), el film de Gillo Pontecorvo sobre los campos de concentración. El texto afirma de manera categórica:

Observen, en Kapo, el plano en que Riva se suicida arrojándose sobre los alambres electrificados: el hombre que en ese momento decide hacer un travelling hacia delante para encuadrar el cadáver en contrapicado, teniendo el cuidado de inscribir exactamente la mano levantada en un ángulo del encuadre final, ese hombre merece el más profundo desprecio" (1961, p. 54).

Kapo no nos ahorra los golpes bajos ni la crueldad ni el sentimentalismo ni la demagogia que componen esa enciclopedia habitual en las películas sobre los campos de concentración. De manera incansable, Pontercorvo enumera los padecimientos de los inocentes, las traiciones, las miserias y las bajezas de los prisioneros, la dignidad suicida de los héroes, el sadismo de los nazis y hasta el amor en medio del espanto. De todos modos, es evidente que Rivette exagera: aquí, como siempre, su método crítico descansa en la elegancia provocativa de las hipérboles. No es para tanto, podríamos decir. Pontecorvo no es abyecto ni despreciable; aunque es ciertamente un director demasiado convencional y demasiado oportunista como para enfrentarse a un tema que requería un tratamiento excepcionalmente lúcido. Pero ésa es justamente la cuestión que plantea Rivette: allí donde la ética resulta inescindible del procedimiento. ¿Cómo filmar la muerte? ¿Cuál es la distancia adecuada para asistir a ese momento sin profanarlo? El problema radica en todas las preguntas que el plano de Pontecorvo no contiene. "Hay cosas -dice Rivette- que deben abordarse con miedo y temblor; la muerte sin duda es una de ellas; ¿cómo se puede filmar algo tan misterioso sin sentirse un impostor?” (p. 54).

Pontecorvo subraya la situación (cree que es necesario subrayar la situación), como si sólo estuviera calculando el impacto que debería provocar la muerte del personaje. Y ese subrayado hace que la imagen se vuelva obscena. Mientras que Moullet celebra la maestría de la puesta en escena en Fuller y no presta atención al tema de sus films, Rivette afirma que Pontecorvo es un impostor que intenta esconderse detrás de un tema irreprochable; pero su bajeza moral queda al descubierto gracias a ese pequeño travelling de acercamiento para reencuadrar el cadáver electrocutado. Moullet dice sobre Fuller: no tiene importancia que esté animado por ideas fascistas porque eso no se traduce en sus travellings. Rivette, en cambio, dice: Pontecorvo es despreciable porque su film es abyecto, y esa abyección se lee en el modo de planificar sus travellings. Lo que importa es la forma, pero no porque permita mantenerse a resguardo de la ideología sino porque es ahí donde justamente se revela la ideología. ${ }^{5}$

En este pasaje entre "La morale est affaire de travellings" y "Le travelling est affaire de morale" se anuncia ya el cambio de dirección que va a experimentar la revista a mediados de la década. Para ese momento, los postulados iniciales de la política de los autores terminarán por escindirse y comenzarán a desarrollarse en direcciones diferentes. De un lado, la insistencia en el estilo de ciertos cineastas no podrá sino derivar hacia una preocupación por aislar la pureza absoluta de la puesta en escena en tanto que sistema autónomo, incontaminado por el mundo. Del otro lado, esa misma política de los 
autores conducirá inevitablemente hacia una axiología de la obra. Y en esa valoración, las estrategias del film no podrán eludir una imbricación con el contexto, poniendo de manifiesto cómo cada director hace que lo real produzca sentidos. Digamos: el film ya no se constituye a partir de la distancia que establece con el mundo sino, al contrario, a partir de la manera en que se entremezcla con él. Proyectado sobre la arena pública (y el cine siempre está llamado a intervenir en el ágora) el principio moral deviene político.

Del fetichismo de la mise en scène, tan cultivado a principios de los 60, Cahiers derivará hacia un discurso sobre la ideología del dispositivo que marcará el fin de la década: la imagen que produce la cámara es un instrumento de dominación porque está construida para convalidar la ideología burguesa. El efecto de realidad del cine dominante -el realismo entendido aquí como censura ideológica- convalida un régimen de visión, artificial pero naturalizado, y produce una forma de conocimiento imaginaria ( $\mathrm{falsa}$ ) que debe contrarrestarse con un conocimiento real. Tal como sostienen Narboni y Comolli en un texto clave, la realidad reproducida fielmente por la cámara es enteramente ideológica:

En este sentido, la teoría de la 'transparencia' (el clasicismo cinematográfico) es eminentemente reaccionaria: no es el mundo en su 'realidad concreta' el que es 'tomado' por (o, más bien, el que impregna) un instrumento no intervencionista, sino el mundo vago, no formulado, no teorizado, impensado, de la ideología dominante. (1969, p. 12)

Si el empirismo es una "ideología de lo visible", se trata de averiguar cuánto saber pueden producir las películas y hasta qué punto ese saber puede transformar nuestra concepción del cine. Ver no es comprender. Entiende aquel que sospecha de lo que ve.

Consideraciones finales: Serge Daney y la alteridad como forma

Pero no son Narboni y Comolli quienes continuarán la huella crítica abierta por Rivette sino Serge Daney en un texto tardío escrito a comienzos de los 90 . Según él, el problema con Pontecorvo es que intenta obtener imágenes bellas ahí donde sólo hay que pensar en imágenes justas. "El travelling de Kapo", es uno de sus últimos escritos: el crítico admite que nunca vio la película y, en realidad, ya nunca la verá (en el reconocimiento de la omisión hay que inferir una incompletud irremediable porque se sabe enfermo de Sida). No vio la película aunque, de alguna manera, sí la vio porque Jacques Rivette se la mostró con palabras definitivas en el viejo artículo publicado en Cahiers du cinéma. Hay algo deslumbrante en esa certeza, tan blindada como arbitraria, que asiste al crítico para dictaminar qué es y qué debe hacer el cine. No hace falta más. Basta con dejarse convencer y creer en eso. Rivette decía que no es posible filmar la muerte sin sentirse un impostor; Daney completa: "Pontecorvo no tiembla ni tiene miedo; los campos de concentración sólo lo indignan ideológicamente" (1998, p. 33).

¿Por qué las imágenes deben ser justas (y sólo pueden pretender ser bellas en la medida en que son justas)? Daney reescribe el texto de Rivette y hace explícita una dimensión que antes sólo podía intuirse. Se trata, precisamente, de ir en contra de ese pecado original del cine que es su vocación de espectáculo: los grandes cineastas son aquellos que se hacen cargo de esa pesada herencia y aceptan que filmar es una manera de ser innoble. ¿Cómo darle la espalda a esa imagen espectacular? Dejando ver, en lo que se muestra, que eso no es todo lo que hay para ver. En vez de celebrar una mirada satisfecha consigo misma, una imagen auténtica se sostiene sobre la tensión no reconciliada entre lo que un plano muestra y lo que inevitablemente debe obturar para poder mostrar algo. Si el texto de Daney es la última estación de ese recorrido que se había iniciado con el comentario de Moullet es porque, al apropiarse del juicio de Rivette, pone en primer plano el vínculo entre forma y moral de una manera categórica.

'El travelling de Kapo' -dice el crítico- fue mi dogma portátil, el axioma que no se discutía, el punto límite de todo debate. Con cualquiera que no sintiera de inmediato la abyección del 'travelling de Kapo' yo no tenía definitivamente nada que ver, nada que compartir (Daney, 1998, p. 22).

El travelling de Kapo se convirtió tempranamente en el "dogma portátil" de Daney porque anticipaba en miniatura todos los vicios contra los que edificará su ética de la imagen. ¿Qué derecho asiste al cineasta para filmar un plano y no otro? ¿Cómo aproximarse a una imagen y hasta dónde? ¿Cuál es la legitimidad de un procedimiento? Tal como quería Welles, un director de cine es un piloto de tormentas que debe tomar decisiones permanentemente y cuyo mayor peligro es encallar entre los acantilados del espectáculo. Mostrar no es exponer inopinadamente aquello que la cámara ha registrado; si es un gesto que permite ver es, justamente, porque obliga a ver. Ver un film es volver a ver algo ya visto por otro. Por lo tanto, el cine es un arte del presente no porque transparente el mundo sino porque, cada vez, actualiza una mirada. Una mirada que se enuncia en presente. Como si permanentemente el 
film dijera: "esto es lo que veo" y no "esto es lo que hay". Puesto que sólo veremos de lo real aquello que el film recorta, el cineasta queda investido de una gran responsabilidad cada vez que toma una decisión sobre sus procedimientos. Una imagen auténtica será aquella que se asume como imagen, aquella que admite que hacer ver algo es también dejar de ver otra cosa, aquella que reconoce que lo mostrado es inevitablemente una parte.

Se trata de una cuestión de forma, sin duda, pero es que hay una moral de los procedimientos y es allí en donde se juega toda la verdad del cine. Pontecorvo es un impostor porque pretende embellecer una escena que sólo pide ser atestiguada y Kapo es un film abyecto porque sólo procura la elegancia de un movimiento de cámara sin evaluar su necesidad, sin pensar responsablemente en la adecuada distancia que debe mantener. Si Daney reconoce en Noche y niebla la forma correcta de abordar el mismo tema es porque advierte en Resnais un pudor y un temor ante el misterio de la muerte que están completamente ausentes en las imágenes de Pontecorvo. Noche y niebla sabe que eso es irrepresentable, pero también sabe que la única justificación del cine es la empecinada decisión de golpearse la cabeza contra esa imposibilidad. Es evidente que el film fracasará en su intento, pero será un fracaso luminoso. ${ }^{6}$

¿Cómo traducir en imágenes aquello que es, por definición, inimaginable? Cómo mostrar: para Resnais en eso consiste el problema; Pontecorvo, en cambio, nunca logra trasladar a sus imágenes la indignación ideológica que le producen los campos de concentración. En esa mínima distancia cabe toda la moral del cine. "Llamo imagen - dice Daney - a lo que se apoya aún sobre una experiencia de la visión y visual a la verificación óptica de un procedimiento de poder - ya sea tecnológico, político, publicitario o militar-, procedimiento que sólo suscita comentarios claros y transparentes. Evidentemente, lo visual concierne al nervio óptico pero, aun así, no es una imagen. Pienso que la condición sine qua non para que haya imagen es la alteridad".

\section{Referencias}

Comolli, J-L. y Narboni, J. (1969). Cinéma / ideologie / critique. Cahiers du cinéma (216), 11-15.

Daney, S. (1998). Perseverancia. Conversaciones con Serge Toubiana. Buenos Aires: El Amante.

Daney, S. (2004). Cine, arte del presente, Buenos Aires: Santiago Arcos.

De Baecque, A. (2003). La cinéphilie, La cinéphilie. Invention d'un regard, histoire d'une culture 1944-1968. París: Fayard.

Dilorio, S. (2005). The Woodcutter's Gaze: Luc Moullet and Cahiers du cinéma 1956-1969. SubStance 34 (3), $79-95$.

Domarchi, J., Doniol-Valcroze, J., Godard, J-L., Kast, P., Rivette, J. y Rohmer, E. (1959). Hiroshima, notre amour. Cahiers du cinéma (97), 1-18.

Fuller, S. (director). (1951). Casco de acero (The Steel Helmet) [Película]. Deputy Corporation.

Fuller, S. (director). (1953). El rata (Pick up on South Street) [Película]. Twentieth Century Fox.

Fuller, S. (director). (1954). El Diablo de las aguas turbias [Película]. 20th Century Studios.

Morrey, D. y Smith, A. (2009). Jacques Rivette. Manchester: Manchester University Press.

Moullet, L. (1958). Ré-creation par la recreation (Tarnished Angels). Cahiers du cinéma (87), 54-55.

Moullet, L. (1959). Sam Fuller sur les brisées de Marlowe. Cahiers du cinéma (93), 11-19.

Moullet, L. (1961). La splendeur du paradoxe (Le Port de la drogue). Cahiers du cinéma (121), 47-50.

Moullet, L. (2014). Piges Choisies. De Griffith à Ellroy. París: Capricci.

Pontecorvo, G. (director). (1960). Kapo [Película]. Cineriz, Vides Cinematografica, Zebra Films.

Resnais, A. (director). (1956). Noche y niebla (Nuit et bruillard) [Película]. Argos Films.

Resnais, A. (director). (1959). Hiroshima mon amour [Película]. Argos Films, Como Films, Daiei Studios.

Resnais, A. (director). (1963). Muriel [Película]. Argos Films, Alpha Produtions, Eclair

Rivette, J. (1961). De l'abjection. Cahiers du cinéma (120), 54-55.

Sirk, D. (director). (1957). Los diablos del aire (The Tarnished Angels) [Película]. Universal Pictures.

Truffaut, F. (1954). Sir Abel Gance. Arts (479), 1-7.

Welles, O. (director). (1958). Sed de mal (Touch of Evil) [Película]. Universal International Pictures. 
1 Antoine de Baecque señala esta circunstancia: “Las palabras 'comunismo' y 'comunistas' fueron sistemáticamente reemplazadas, en la banda sonora, por 'droga' y 'traficantes'. Si el nerviosismo de Richard Kiley, que interpreta al principal agente comunista, puede ser igualmente el de un hombre con síndrome de abstinencia, muchos espectadores deben haberse preguntado por qué los norteamericanos esconden drogas en microfilms de fórmulas químicas y matemáticas...” (2003, p. 174). Sobre esta cuestión, véase también Moullet, 1961.

2 Moullet defiende tan encarnizadamente a Fuller que, cuando el realizador lee sus artículos, decide suscribirse a Cahiers du cinéma. El crítico ha dicho que es un cineasta del instinto y que sabe apreciar el espectáculo del mundo natural: un "poeta telúrico". Por eso es el que mejor sabe cómo filmar el cuerpo humano y, en particular, los pies (la parte del cuerpo que está en contacto con la tierra). El mejor hombre es aquel que tiene los pies más fuertes. En el paroxismo de su celebración crítica, Moullet concluye que es "el único cineasta que filma con los pies". Y eso debe ser entendido aquí como el mayor elogio. El director le escribe una carta de agradecimiento y agrega un paquete al envío: una pierna de muñeca de plástico con el autógrafo "Samuel Fuller”.

3 Como dirá el propio Moullet años más tarde: “Una pequeña frase de este texto ha hecho más por mi reputación que todas mis películas juntas” (2014, p. 87).

$4 \quad$ Para una interpretación diferente sobre el vínculo entre travelling y moral en Moullet y Godard, véase Dilorio, 2005.

5 Sobre el texto de Rivette, véase Morrey y Smith, 2009. Para Rivette, forma y contenido son inseparables: la mise en scène es una cuestión moral porque expresa el punto de vista del cineasta sobre el mundo. Se podría decir: Pontecorvo filma mal porque piensa mal.

${ }_{6}$ Daney opone el film de Pontecorvo a Noche y niebla. En otro lugar, se refiere al concepto de Blanchot sobre la "escritura del desastre" para referirse a esos "tres manuscritos" de Resnais, "esos tres testigos irrecusables de nuestra modernidad" que son Noche y niebla, Hiroshima mon amour y Muriel. El cine de Resnais en los años 60 aparece así como el gran "sismógrafo”, aquel que encontró la forma para contar el acontecimiento fundante de nuestra modernidad (Véase Daney, 2004). 